$9-1-2020$

\title{
Informing social and behavior change programs: Using social listening and social monitoring
}

Breakthrough RESEARCH

Follow this and additional works at: https://knowledgecommons.popcouncil.org/departments_sbsr-pgy

Part of the Health Communication Commons, and the Public Health Commons How does access to this work benefit you? Let us know!

\section{Recommended Citation}

Breakthrough RESEARCH. 2020. "Informing social and behavior change programs: Using social listening and social monitoring," Programmatic Research Brief. Washington, DC: Population Council. 


\section{KEY MESSAGES}

- People throughout the world increasingly use social media to express themselves and engage in conversations about their lives and their health.

- Social and behavior change programs can leverage social listening to gather insights related to people's health-related knowledge, attitudes, and behaviors.

- Insights generated through social listening and social media monitoring can be used together with other monitoring and evaluation techniques to produce data-rich learning environments for program design and adaptation.
FIGURE 1. SOCIAL MEDIA USERS REACHED OVER 3 BILLION IN 2020

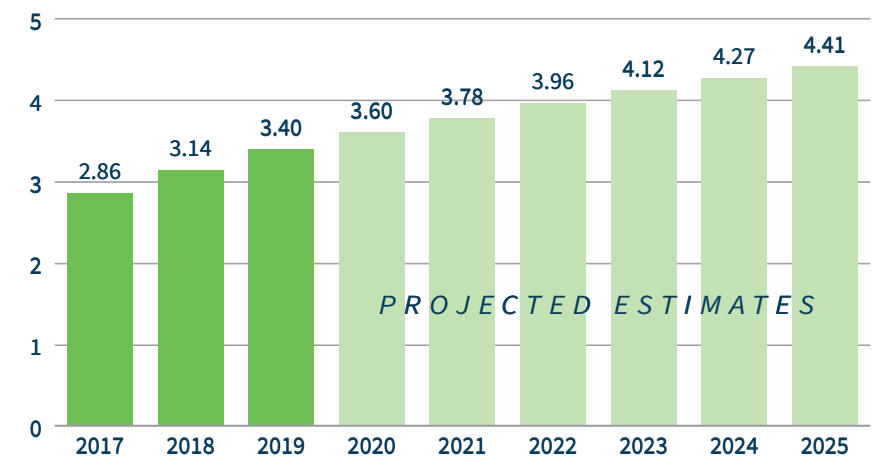

Source: Statista, Dossier: Social Media Usage Worldwide (2020),

https://www.statista.com/study/12393/social-networks-statista-dossier/.

program managers to measure audiences reached and conversation sentiment. ${ }^{4}$

These methods are of increasing relevance to SBC work in United States Agency for International Development (USAID) priority countries because internet and social media use are growing steadily there. In Francophone West Africa in 2017, Côte d'Ivoire's internet usage was $44 \%$, while usage in Burkina Faso, Togo, and Niger was approximately 16\%, 12\%, and $10 \%$, respectively, and rising. Men in sub-Saharan Africa are the primary internet users, revealing a gender gap in which women are $15 \%$ less likely than men to own a mobile phone and $41 \%$ less likely than men to use mobile internet. ${ }^{5}$ Similarly, social media use is higher among men than women in the region, with women representing between one in three users of Instagram and one in four users of Facebook. ${ }^{6}$

Despite low- and middle-income countries' relatively small shares of populations using the internet and the gap between genders, their users spend about one hour more per day on social media than those in the United States. Globally, younger people in low- and middle-income countries spend two to three times longer on social media compared to older people.? As internet usage continues to grow in these countries, the volume of social media conversation will rise, further increasing the availability of social media-related data, particularly for younger populations.

Public health programs can leverage methodologies such as social listening and social monitoring, traditionally used in marketing, to gather insights on health-related knowledge, attitudes, and behaviors expressed through online interactions. These insights can be used in conjunction with other traditional monitoring and evaluation techniques to produce data-rich learning environments for program design and periodic programmatic adaption. 


\section{How Is Social Listening Conducted?}

Social listening uses existing data from public online sources. It can be conducted both retrospectively and prospectively, enabling SBC program, research, and evaluation stakeholders to access relevant insights in a quick and cost-effective way. Platforms in which social listening can be conducted include Facebook, Instagram, Reddit, Twitter, YouTube, blogs, and news sites, among others.

Advancements in the development of machine learning algorithms for text analysis have expanded our capacity to rapidly collect and analyze social media data. For example, the LexRank machine learning algorithm can identify the most representative posts in a conversation, and the Crimson Hexagon/Brandwatch Brightview software can classify posts by topic. ${ }^{8}$

By leveraging the power of this software for social listening, analysts can: 1) identify key conversation terms and construct Boolean search strings using translated terms in all languages required; 2) set the listening or monitoring period of interest; 3 ) target one or more social media platforms; and 4) work with social media analysis software programs and machine learning software.

For social monitoring, the sources are limited to the social media channels used by the relevant SBC program. Program implementers may set up hashtagmonitoring systems to track engagement metrics and reactions to campaigns or content of interest. For example, a program may monitor posts on a campaign's Facebook or YouTube page while also tracking hashtags related to the campaign used on other social media platforms.

Information collected through the social listening process is analyzed for patterns in posts at scale to determine volume of posts; spikes in engagement; and drivers of conversation, sentiment, and audience affinities, among other characteristics. This analysis can be similar to an analysis of qualitative data from other sources. During this process, all posts used for analysis or featured in reports must be anonymized by removing names and profile pictures. Social listening platforms do not automatically anonymize posts, but it should be done by analysts to confer identity protections or, if in the context of research, abide by ethical human-subject requirements. Finally, the information is shared with program managers to determine how to use the findings to improve the design and adapt the program.

\section{Social Listening and Social Monitoring to Inform SBC Programs in Francophone West Africa}

Breakthrough RESEARCH is working with our resource partner, M\&C Saatchi, to apply social listening and social monitoring to inform SBC programs throughout Francophone West Africa. ${ }^{9}$ We provide examples from our experiences using these methods of the USAID-supported activities Merci Mon Héros and Resilience in the Sahel Enhanced (RISE) II.

\section{The Merci Mon Héros Campaign}

Breakthrough RESEARCH's sister program, Breakthrough ACTION, is implementing a mass and social media campaign called Merci Mon Héros (MMH) in nine countries in Francophone West Africa (see Figure 2). The campaign aims to: 1) encourage young people to talk about their family planning and reproductive health (FP/RH) realities; 2) encourage adults to overcome restrictive social and gender norms to talk about FP/RH with young people; and 3) stimulate discussion between young people and adults to identify, address, and shift restrictive social norms and remove the shame and taboos that prevent young people from accessing FP/RH information and services. ${ }^{10}$

\section{SOCIAL MEDIA MONITORING KEY TERMS}

Total potential impressions: The number of people who could have seen any given post based on the number of followers of those who engaged with the post.

Total reach: The number of people who saw a post at least once. Reach is defined by Facebook as "the total number of people who had any content from your page or about your page enter their screen." ${ }^{15}$

\section{Total engagement/conversation volume}

The total number of times people engaged with posts through reactions, comments, shares, retweets, mentions, and likes.

Sentiment: The overall positivity or negativity featured in a post. It reflects the tone of the keywords used in a post and is measured by analyzing those keywords. 
FIGURE 2. MERCI MON HÉROS

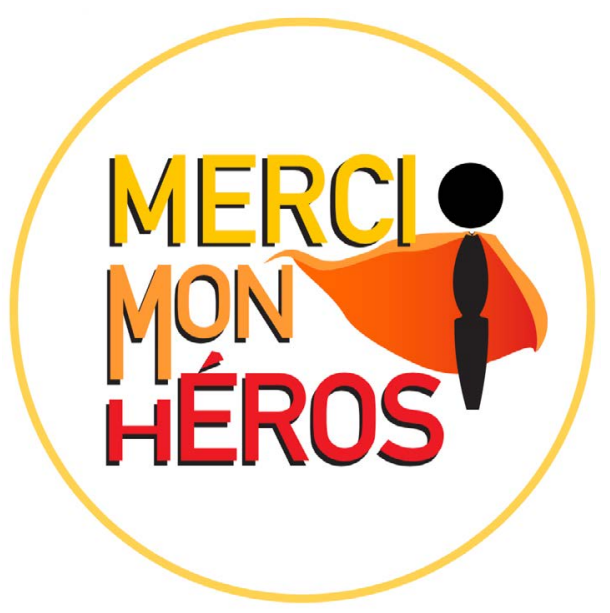

Source: Merci Mon Héros Campaign.

The MMH campaign was developed by youth through an initiative supported by Breakthrough ACTION and launched online in November 2019, primarily through Facebook. MMH campaign messages were also disseminated through other traditional media channels and community-level events. Campaign content included original testimonial videos featuring youth and adults discussing topics such as first periods, first sex, first pregnancies, first relationships, and family planning methods.

Breakthrough RESEARCH uses social listening to monitor and evaluate the MMH campaign in Burkina Faso, Côte d'Ivoire, Niger, and Togo in conjunction with other research methods. The social listening component helps stakeholders to:

- Identify knowledge and attitudes toward key FP/RH topics in target countries.

- Detect engagement with the MMH campaign content and provide recommendations for program adaptation.

- Recognize how knowledge and attitudes regarding key FP/RH topics changed over time.

A social listening report covering the period of November 2018 to November 2019 helped identify themes, such as the role of gender and partner communication, to incorporate into new campaign videos. ${ }^{11}$ Figure 3 shows the campaign's timeline and volume of conversation on Facebook. Peaks in the line graph illustrate significant engagement and the

FIGURE 3. MONITORING ENGAGEMENT WITH THE MERCI MON HÉRO CAMPAIGN

Conversation Volume, November 1-June 10, 2020
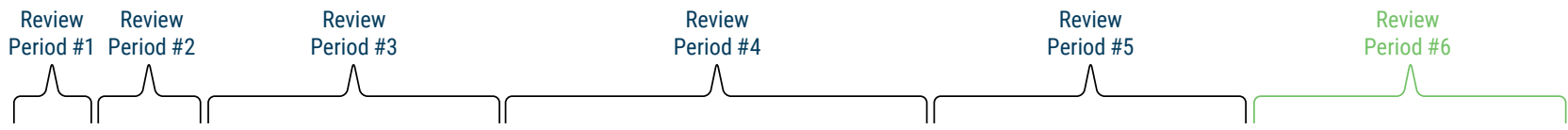

900

800

700

600

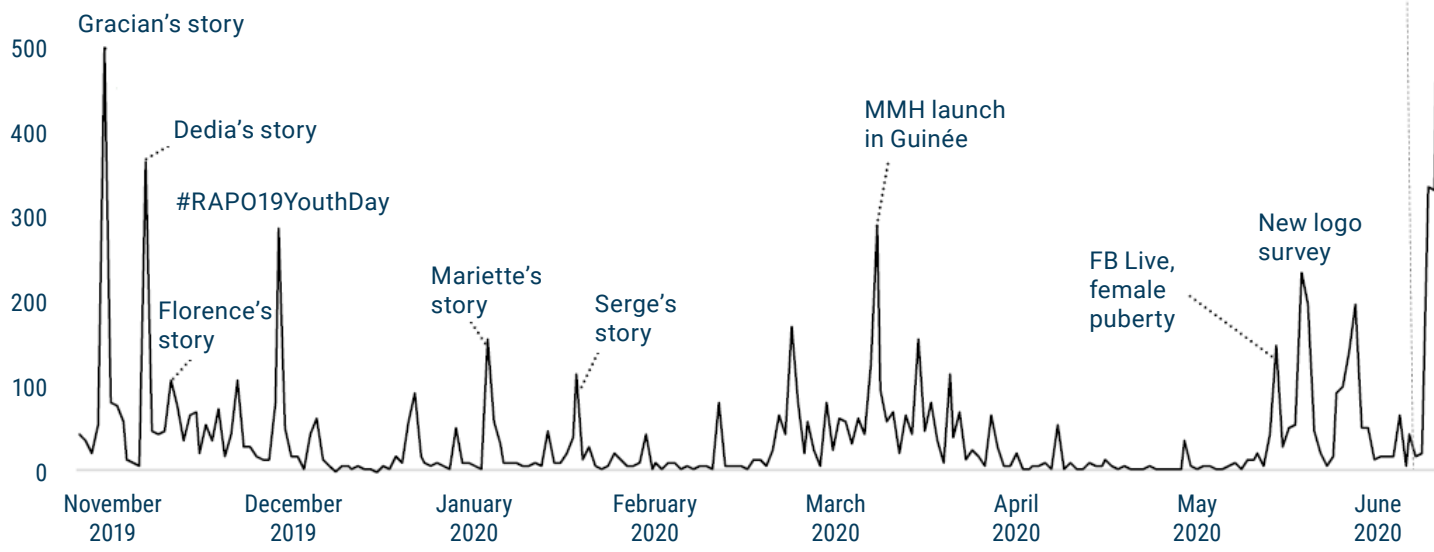

FB Live,

menstrual cycle

Fanta's story

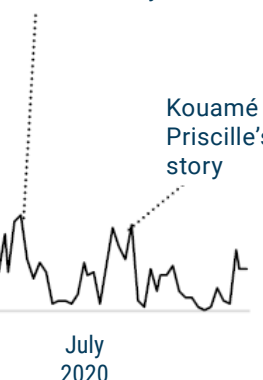

Source: Breakthrough RESEARCH. 2020. "Merci Mon Héros.” Social Listening Monitoring Report\#6. Washington, DC: Population Council. 
content or events driving responses on social media. ${ }^{12}$ Between Nov. 1, 2019, and July 30, 2020, 24,023 organic engagements occurred across social media channels directly related to the $\mathrm{MMH}$ campaign content, including shares, retweets, mentions, and Facebook comments in response to videos. These reports have informed the MMH strategy. For example, one finding indicated the campaign was reaching mainly youth and younger adults (ages 18 to 34), but not the older adults who are a critical audience for inspiring intergenerational communication to break taboos about discussing reproductive health. In response, youth leaders created additional online content specifically oriented toward older adults.

\section{The Resilience in the Sahel Enhanced (RISE) II Program}

USAID's Resilience in the Sahel Enhanced (RISE) II program targets chronically vulnerable populations through approaches to improve priority behaviors in maternal, newborn, and child health (MNCH); family planning; nutrition; and water, sanitation, and hygiene. The program is implemented at the community and facility levels through four Development Food Security Assistance partners and health service delivery mechanisms in selected zones in Burkina Faso and Niger. ${ }^{13}$ To support these implementation partners, Breakthrough ACTION provides capacity strengthening and technical assistance to the partners to improve coordination and enhance the quality and alignment of the program's SBC components.

Breakthrough RESEARCH uses social listening and social monitoring to help RISE II implementers identify needs and priorities among target audiences within communities for situation analysis and planning. Breakthrough RESEARCH surveys social media and press coverage sources to explore online conversations and identify beliefs, attitudes, and expressed social norms across health topics, including $\mathrm{MNCH}$, nutrition, and water, sanitation, and hygiene.

Preliminary findings from social media and press coverage conversations provide insights regarding how young women feel social pressure to maintain traditional practices from older women related to pregnancy and childbirth. For example, as the tweets in Figure 4 show, some older women may encourage young mothers to avoid the hospital or to adopt cultural practices that may not be in the best interest of the child, and this pressure may be difficult to avoid.

\section{FIGURE 4. SOCIAL MEDIA PROVIDES INSIGHTS INTO ATTITUDES AND BEHAVIORS}

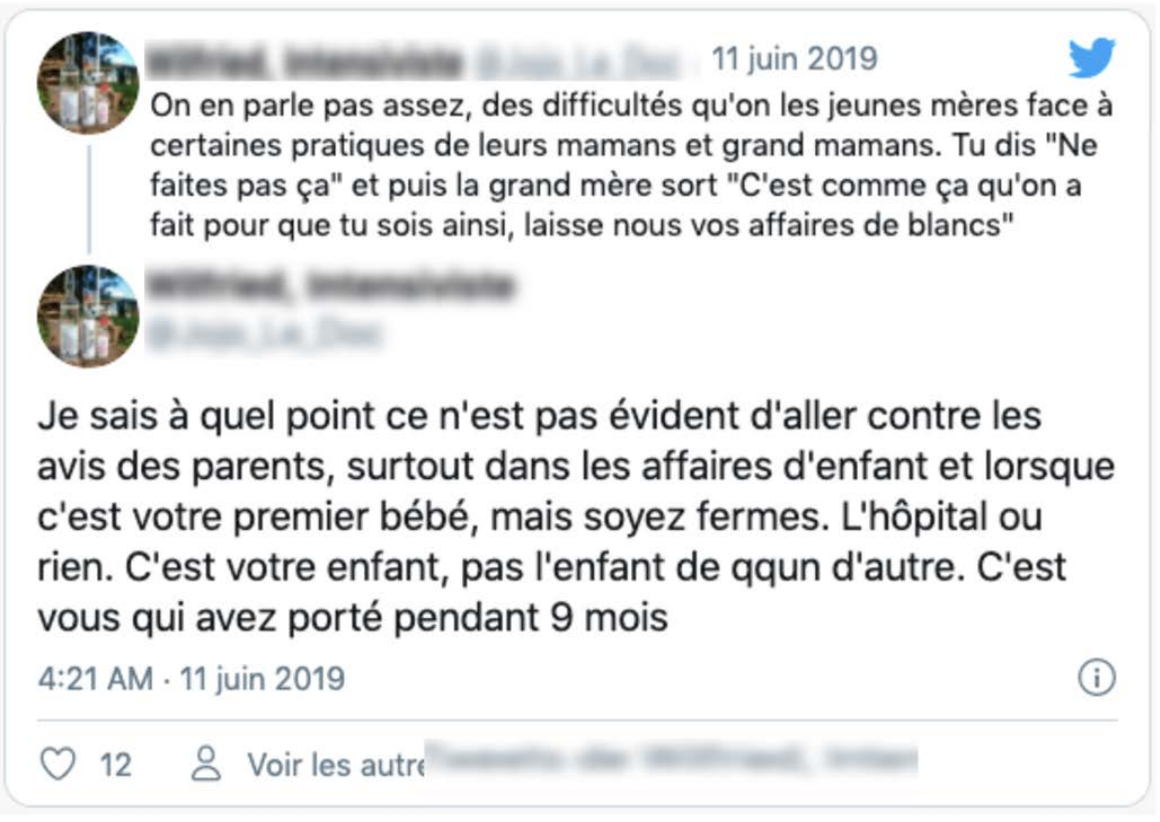

\section{Translation:}

"We don't talk about it enough, about the difficulties that the young mothers face in front of certain practices of their mothers and grandmothers. You say 'don't do that' and then the grandmother says, 'That's how we did it so that you can be like that, forget the stuff from the whites'."

"I know how hard it is to go against the advice of parents, especially in children's matters and when it's your first baby, be firm. Hospital or nothing. It's your child, not anyone else's child. It is you who has been carrying [the child] for nine months." 


\section{The Strengths of Using Social Listening and Social Monitoring to Inform SBC Programs}

Social listening and social monitoring present many advantages for people implementing, monitoring, or conducting research about SBC programs, including communication campaigns.

- Social listening is a highly flexible tool, giving program implementers and researchers the ability to analyze data retrospectively or prospectively, in short- or long-time intervals as the volume of conversation allows.

- Rapid insight generation can be attained through social listening and social monitoring of data already present in online forums and social media platforms. The timeline from study concept development to insight generation can be just a fraction of that involved in traditional research.

- Technology is evolving very quickly, and social listening and social monitoring techniques will likely become more sophisticated and lead to better understanding of target audiences' feelings.

\section{The Limitations of Using Social Listening and Social Monitoring to Inform SBC Programs}

While social listening and social monitoring offer opportunities to rapidly collect information from online conversations regarding beliefs, attitudes, and social norms and behaviors, several limitations should be considered.

- Generalizing of online data is a risk. Due to the inequalities in access to the internet and social media use, social listening data cannot be considered representative of the general population and therefore findings cannot be generalized. This issue is further compounded by the fact that privacy considerations pose limitations to how much we know about who posts messages, particularly on platforms like Facebook and Instagram.
- Conversation volume should not be considered a perfectly precise measure. First, the search string is constructed to minimize irrelevant conversation and cannot be $100 \%$ effective. Second, some posts could feasibly sit across multiple topics, yet are assigned to just one topic.

- Topic sentiment is difficult to determine in written language, despite increased sophistication in the tools that analyze language. This difficulty is particularly true when the topic itself frequently manifests in language typically considered negative, such as "sexual abuse."

- Bots, or computer programs intended to disrupt conversations, can spread false messages or create confusion. Depending on the topic, it may be necessary to review accounts or messages to separate out those that are not from real users. ${ }^{14}$

- Other biases may be present but not visible. Are people taking certain positions because they feel they will receive a benefit from their friends/ followers? Are social media posters more or less likely to voice their real beliefs and opinions online rather than when talking to someone face to face, such as during more traditional qualitative research?

\section{Social Media Is a New Source for Program Learning and Adaptive Management}

The growing use of social media platforms provides an exciting opportunity to leverage online conversations to monitor and inform SBC programs, particularly in countries with high internet use. Insights generated through social listening and social monitoring can be used in conjunction with other traditional monitoring and evaluation techniques to create data-rich learning environments for periodic programmatic decisionmaking and ultimately improve program performance. Global and regional SBC program implementers, evaluators, and donors in USAID priority countries should consider incorporating social listening and social monitoring in their toolbox of methods to provide feedback for learning and adaptive management of programs. 


\section{References}

1 Simon Kemp. 2020. "Digital 2020: 3.8 billion people use social media," We Are Social, Jan. 30. https://wearesocial.com/ blog/2020/01/digital-2020-3-8-billion-people-use-social-media.

2 Due to privacy restrictions, Whatsapp is not considered a publicly accessible social media tool.

3 Tony Train. 2020. "What Is Social Listening, Why It Matters, and 10 Tools to Make It Easier," Hootsuite, March 3, https://blog.hootsuite.com/social-listening-business/\#whatis

4 —What Is Social Listening, Why It Matters, and 10 Tools to Make It Easier."

5 GSM Association, Connected Women: The Mobile Gender Gap Report 2019 (2019), https://www.gsma.com/

mobilefordevelopment/wp-content/uploads/2019/02/ GSMA-The-Mobile-Gender-Gap-Report-2019.pdf.

6 NapoleanCat Stats, https://napoleoncat.com/stats/.

7 GlobalWeblndex, Social: Flagship Report 2018, https://www.globalwebindex.com/hubfs/Downloads/ Social-H2-2018-report.pdf.

8 Erkan, Güneş, and Dragomir R. Radev. 2004. "LexRank: Graphbased lexical centrality as salience in text summarization," Journal of Artificial Intelligence Research 22: 457-79; for more information go to https://www.brandwatch.com.

9 For more information on the Breakthrough RESEARCH Project, go to https://breakthroughactionandresearch.org/about/ breakthrough-research/.

10 For more information on the Breakthrough ACTION Project, go to https://breakthroughactionandresearch.org/about/ breakthrough-action/.

11 Breakthrough RESEARCH. 2020. "Family planning in West Africa baseline understanding: A social listening report," Breakthrough RESEARCH Technical Report. Washington, DC: Population Council.

12 Breakthrough RESEARCH. 2020. "Merci Mon Héros social listening report \#6: July 2020," Breakthrough RESEARCH Technical Report. Washington DC: Population Council.

13 Dougherty, Leanne and Jessie Pinchoff. 2020. "Evidence to inform an integrated social and behavior change strategy in the Sahel," Breakthrough RESEARCH Literature Review. Washington, DC: Population Council.

14 Broniatowski, David A. et al. 2018. "Weaponized health communication: Twitter bots and Russian trolls amplify the vaccine debate," American Journal of Public Health 108: 1378-84.

15 FACEBOOK for Business, "Reach," https://www.facebook.com/ business/help/710746785663278.

\section{Acknowledgments}

Data presented in this brief were collected and analyzed in partnership with M\&C Saatchi. We acknowledge Laura Reichenbach and Paul Hewett of the Population Council for their technical guidance and review; Nancy Matuszak at Population Reference Bureau for editorial support; Prographics for design support; and Lindsay Swisher, Joan Kraft, and Alaa Al-Bashir with the United States Agency for International Development (USAID), who provided valuable feedback during the development of this brief.

Suggested citation: Breakthrough RESEARCH. 2020. "Informing Social and Behavior Change Programs Using Social Listening and Social Monitoring," Breakthrough RESEARCH Programmatic Research Brief. Washington DC: Population Council.

Photo credit: Merci Mon Héros, John Hopkins Center for Communication Programs

๑ 2020 The Population Council. All rights reserved.

\section{Breakthrough RESEARCH, Population Council}

4301 Connecticut Ave., NW, Suite 280

Washington, DC 20008

+1-202-237-9400

breakthroughactionandresearch.org

BreakthroughRESEARCH@popcouncil.org

\section{(i) USAID}

Breakthrough RESEARCH is made possible by the generous support of the American people through the United States Agency for International Development (USAID) under the terms of cooperative agreement no. AID-OAA-A-17-00018. The contents of this document are the sole responsibility of the Breakthrough RESEARCH and Population Council and do not necessarily reflect the views of USAID or the United States Government.

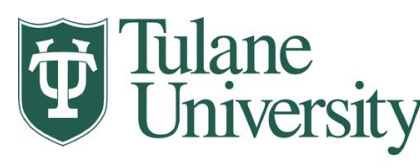

POPULATION COUNCIL

Ideas. Evidence. Impact.

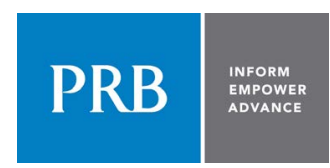

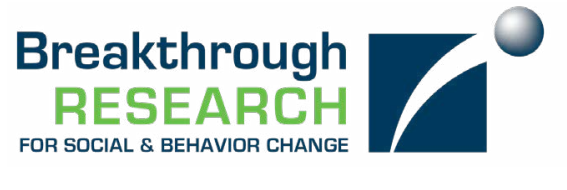

Breakthrough RESEARCH catalyzes social and behavior change (SBC) by conducting state-ofthe-art research and evaluation and promoting evidence-based solutions to improve health and development programs around the world. Breakthrough RESEARCH is a consortium led by the Population Council in partnership with Avenir Health, ideas42, Institute for Reproductive Health at Georgetown University, Population Reference Bureau, and Tulane University. 